\title{
Examining the importance of Aberdeenshire (UK) coastal waters for North Sea bottlenose dolphins (Tursiops truncatus)
}

\author{
Karen A. Stockin* ${ }^{\ddagger \S}$, Caroline R. Weir ${ }^{\dagger \ddagger}$ and Graham J. Pierce* \\ *School of Biological Sciences (Zoology), University of Aberdeen, Tillydrone Avenue, Aberdeen, AB24 2TZ, UK. \\ ${ }^{\S}$ Present address: Coastal-Marine Research Group, Institute of Natural Resources, Massey University, Private Bag 102904, \\ North Shore MSC, Auckland, New Zealand. ${ }^{\dagger}$ Ketos Ecology, 4 Compton Road, Kingsbridge, Devon, TQ7 2BP, UK.

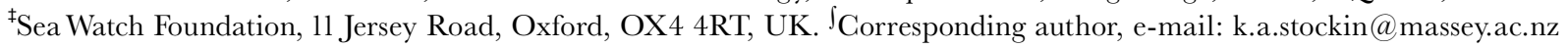

\begin{abstract}
Using land- and vessel-based surveys, data on the relative abundance, distribution and habitat use of bottlenose dolphins (Tursiops truncatus) in Aberdeenshire waters were collected between 1999 and 2001. Bottlenose dolphins were present throughout the year, with peak abundance during the months of March to May. The occurrence of calves was seasonal, with the proportion of calves highest during the spring months. Foraging behaviour was recorded mainly in the vicinity of Aberdeen harbour. Dolphins photographed in Aberdeenshire waters were successfully matched and confirmed as Moray Firth animals. The results of the present study suggest that Moray Firth bottlenose dolphins utilize Aberdeenshire waters more frequently than previously reported. Aberdeen harbour is apparently an important feeding area, and Aberdeenshire waters are regularly used by mother-calf pairs. This has important management implications since this area of coastline does not currently form part of the designated Special Area of Conservation (SAC) for this population.
\end{abstract}

\section{INTRODUCTION}

Cetacean species that inhabit coastal areas, such as the bottlenose dolphin (Tursiops truncatus, Montagu, 1821), are likely to be affected by human activities (Wells et al., 1994). Anthropogenic effects may be of particular concern for small isolated coastal populations, such as may be the case for the North Sea population of bottlenose dolphins that inhabits the Moray Firth, Scotland (UK) (see Figure 1). Under the International Union for the Conservation of Nature and Natural Resources classification, bottlenose dolphins are considered 'data deficient' (Reeves et al., 2003). However, the Moray Firth population is arguably one of the best studied in Europe, with an estimated median population size of 85 individuals (76263, 95\% CI) (Durban et al., 2005). In March 2005, an area of the inner Moray Firth was designated as a marine Special Area of Conservation (SAG) specifically for the conservation of this small population. However, recent evidence suggests North Sea bottlenose dolphins range considerably beyond the boundaries of the Moray Firth and its associated SAC (Wilson et al., 2004).

Under Annex II of the European Union Habitats and Species Directive (92/43/EEG), bottlenose dolphins are considered a priority species for conservation in European waters. However, successful conservation of populations of mobile marine predators depends upon a good understanding of distribution, home range and habitat requirements. Managing a protected population becomes increasingly difficult when factors such as home range and distribution change over time. This is especially true of management options that focus on the protection of specific key sites, such as those designated under Annex II of the European Union Habitats and Species Directive.

Here we examine the occurrence, distribution and habitat use of bottlenose dolphins in the coastal waters of Aberdeenshire, north-east Scotland (UK) from 1999 to 2001. This study site lies over $200 \mathrm{~km}$ south-east of the designated $\mathrm{SAC}$, in a shallow water region of the northwestern North Sea. We report on the presence, relative abundance and behaviour of bottlenose dolphins along the Aberdeenshire coast and discuss the potential importance of these waters in relation to the protected Moray Firth dolphin population.

\section{MATERIALS AND METHODS Data collection}

A combination of dedicated land- and vessel-based surveys was used to monitor the occurrence, relative abundance, distribution and behaviour of bottlenose dolphins along the Aberdeenshire coastline. To ensure adequate standardization and compatibility amongst the observations, only those data collected by seven experienced observers during dedicated surveys were included in the present analysis.

\section{Land-based surveys}

Land-based surveys were conducted between March 1999 and October 2001 from six sites along the Aberdeenshire coast: Collieston, Balmedie, Aberdeen harbour, Girdleness, Nigg and Cove (Figure 1). In addition, 


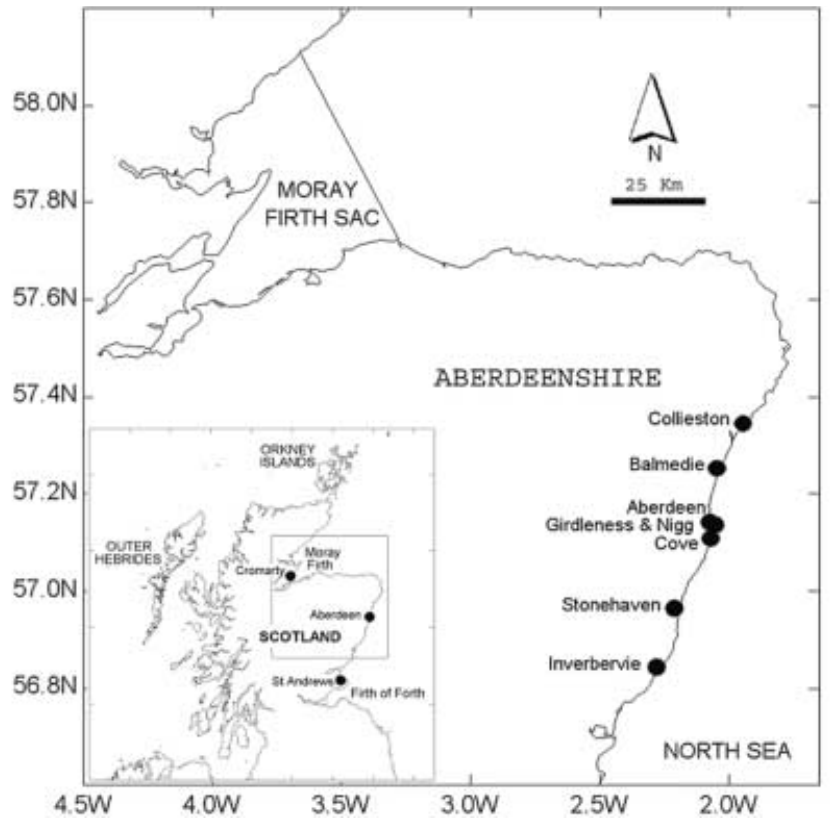

Figure 1. Map showing the location of Aberdeenshire and key study sites relative to the Moray Firth SAC.

records of opportunistic sightings provided by Sea Watch Foundation volunteers were noted, although these were not included in any formal analysis (see Results). The sites were situated at between 15 and $30 \mathrm{~m}$ above sea level, with all observation areas having a $180^{\circ}$ field of view along the coast. Observers applied a continuous scanning methodology (Mann, 1999) using both the naked eye and binoculars $(8 \times$ and $10 \times$ magnification). Animals were effectively surveyed within a $2 \mathrm{~km}$ radius of the coast, although most effort was concentrated within a $1 \mathrm{~km}$ radius of the survey site. Environmental data including sea state, visibility and swell height were recorded every $15 \mathrm{~min}$ throughout each survey, and at the beginning of each cetacean encounter. During each dolphin observation, data relating to group size, composition and behaviour were recorded. Group size was based on minimum group count estimates for each age-class. Calves were defined as animals that were approximately one-half (or less) the length of an adult and were consistently observed in association with an adult animal (Fertl, 1994). Juveniles were defined as animals approximately two-thirds the size of an adult animal and frequently observed swimming independently as well as in association with an adult animal (Mann et al., 2000). For the purposes of analysis we also defined the category 'immatures', referring to animals that were either juveniles or calves. Animals which were deemed too large to classify as either calves or juveniles, and which appeared independent of other animals within the group were defined as adults. During each encounter, ad libitum behavioural sampling (Mann, 1999) occurred and a behavioural category was allocated according to the activity of the majority $(>50 \%)$ of the group. If animals were noted to spend similar amounts of time engaged in more than one activity, then all of the observed behaviours were recorded. Behaviour was classified into six primary categories: forage, normal swim, travel, mill, social and rest, as per the definitions given in
Table 1. Behavioural categories used during field observations of bottlenose dolphins in Aberdeenshire waters.

\begin{tabular}{|c|c|}
\hline $\begin{array}{l}\text { Behavioural } \\
\text { category }\end{array}$ & Description of observed activity \\
\hline Forage & $\begin{array}{l}\text { Dolphins observed in any effort to capture and } \\
\text { consume prey, as evidenced by prey pursuit } \\
\text { and/or fish tosses. }\end{array}$ \\
\hline $\begin{array}{c}\text { Normal } \\
\text { swim }\end{array}$ & $\begin{array}{l}\text { Dolphins involved in steady movement, with } \\
\text { regular and constant surfacing within the same } \\
\text { area. Movements are slower and less consistent } \\
\text { than those observed in travelling behaviour. }\end{array}$ \\
\hline Travel & $\begin{array}{l}\text { Dolphins engaged in persistent directional } \\
\text { movement, often fast and occasionally } \\
\text { porpoising clear of the water, and/or involving } \\
\text { bow-riding of vessels. }\end{array}$ \\
\hline Mill & $\begin{array}{l}\text { Dolphins showing non-directional slow move- } \\
\text { ments within the same location, usually, } \\
\text { staying close to the surface, and no apparent } \\
\text { physical contact between individuals. }\end{array}$ \\
\hline Social & $\begin{array}{l}\text { Dolphins observed chasing and/or engaged in } \\
\text { body contact with each other, including } \\
\text { breaching and aspects of play and/or mating } \\
\text { with other dolphins. }\end{array}$ \\
\hline Rest & $\begin{array}{l}\text { Dolphins observed at the surface but showing no } \\
\text { surface behaviours, usually engaged in slow } \\
\text { movements, and often observed within tight } \\
\text { groups. Resting lacks the active components of } \\
\text { the other behaviours. }\end{array}$ \\
\hline
\end{tabular}

Table 1. Group size, composition and behavioural data were recorded only in circumstances where the group could be accurately assessed, thus not during brief $(<5 \mathrm{~min})$ or distant $(>1 \mathrm{~km})$ observations.

\section{Vessel-based surveys}

Between May 1999 and October 2001, vessel-based surveys were conducted along the Aberdeenshire coastline aboard a $10 \mathrm{~m}$ vessel, MV 'Tranquillity' (mean vessel speed 7 knots, $3.5 \mathrm{~m}$ eye height). A minimum of two experienced observers was on board during each survey, accompanied by between three and six additional volunteers. The vessel predominantly travelled parallel to the shore, usually within $1.5 \mathrm{~km}$ of the coast (Figure 2), although occasionally coverage extended up to $3.5 \mathrm{~km}$ from the coastline. Surveys were carried out using a rotational system of observers watching from both the port and starboard sides of the vessel. Observers applied a continuous scanning methodology (Mann, 1999) using both naked eye and binoculars $(8 \times$ and $10 \times$ magnification), to within a search radius of $1 \mathrm{~km}$ of the vessel. Vessel speed and position were recorded every $15 \mathrm{~min}$ via the onboard Global Positioning System (GPS), and environmental data including Beaufort sea state, visibility and swell height were recorded throughout each survey. At the onset of each encounter with dolphins, a GPS position was noted and environmental and behavioural data were recorded. Data collection continued every $15 \mathrm{~min}$ throughout the duration of each encounter, and a final GPS position was recorded at the termination of each encounter. 


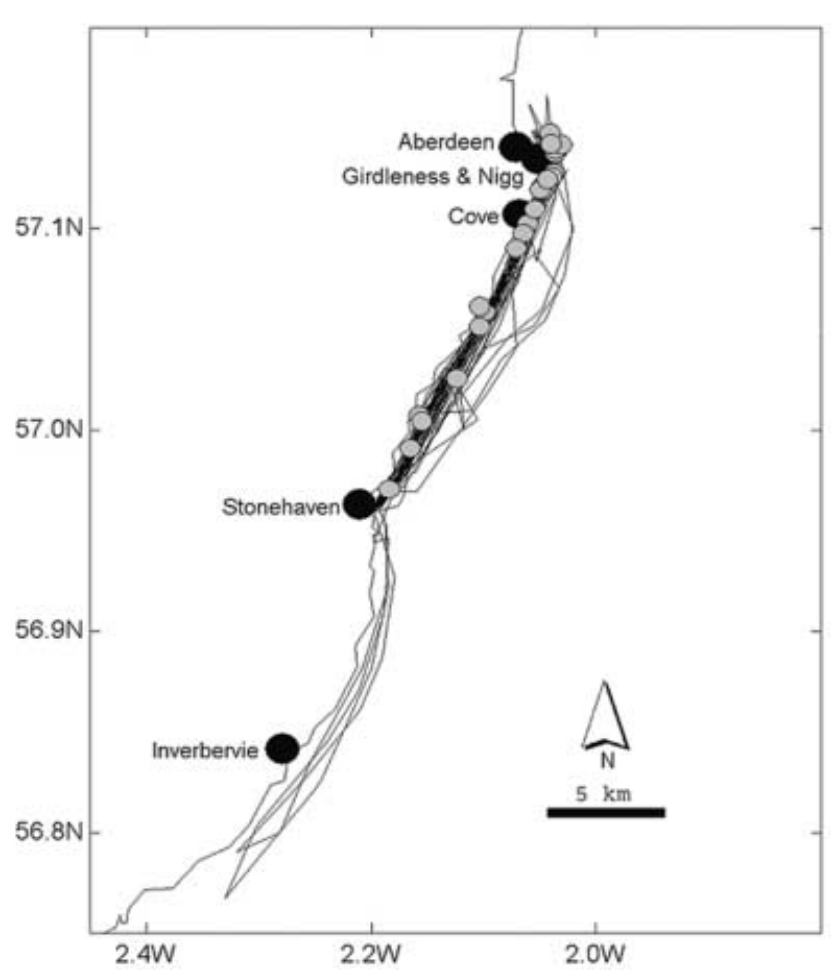

Figure 2. Plot of 26 vessel-based survey routes (lines) and associated bottlenose dolphin sightings (grey dots) in Aberdeenshire waters between 1999 and 2001.

Group size, composition and behavioural data were recorded in the same manner as previously described for land-based surveys. Additionally, to determine whether known individuals from the Moray Firth population were present, photographs of individual bottlenose dolphins were taken during a small proportion of surveys $(\mathrm{N}=6)$, using a Nikon F80 SLR camera and a Nikon-AF Nikkor $75-300 \mathrm{~mm}$ lens.

\section{Data analysis}

We used univariate analyses to investigate the occurrence and relative abundance of bottlenose dolphins along the Aberdeenshire coastline. The occurrence and relative abundance of bottlenose dolphins was calculated as the number of sightings per $60 \mathrm{~min}$ search effort (SPUE) and the number of observed individuals per $60 \mathrm{~min}$ search effort (IPUE) respectively. Variation in the number of sightings, individuals, and group size and composition was analysed separately for land- and vesselbased data. Factors considered include: month, season, locality, sea state and visibility. For temporal analyses, data were segregated into seasonal quarters: spring (March to May), summer (June to August), autumn (September to November) and winter (December to February). Group composition was assessed in terms of the proportions of calves, juveniles and immatures within each group. To account for the effects of environmental conditions on dolphin detection, only surveys conducted in good visibility $(\geqslant 1 \mathrm{~km})$ and in Beaufort sea state of 4 or less were used (after Hammond et al., 2002). The data were initially tested for normality using KolmogorovSmirnov goodness of fit tests (Zar, 1996), and nonparametric Kruskal-Wallis $(\mathrm{H})$ tests were consequently used since the statistical distributions of all datasets were not normal (Zar, 1996). Statistical analyses were carried out using the Statistical Package Minitab ${ }^{\circledR} 14$.

Photo-identification analysis was undertaken using the methods outlined by Wilson et al. (1999). We used a variety of permanent identification marks to recognize individuals, including nicks in the dorsal fin, depigmented areas and skin lesions (Stevick et al., 2001). Animals exhibiting only rake marks $(\mathrm{N}=4)$ were not included in the present analysis since the longevity of such marks is considered to be relatively short for this population (Wilson et al., 1999). Photographs obtained in the present study were compared with catalogued individuals from the Moray Firth population (catalogue held by the University of Aberdeen).

\section{RESULTS}

\section{Survey effort}

Between March 1999 and October 2001, 117 land-based surveys were conducted along the Aberdeenshire coastline, resulting in $218 \mathrm{~h}$ of survey effort with visibility $\geqslant 1 \mathrm{~km}$ and Beaufort sea state 4 or less. The number of survey days per month ranged from 2 to 23 days, with effort during each month ranging from 3 to $30 \mathrm{~h}$ (Table 2). Between May 1999 and August 2001, 29 vessel-based surveys were conducted along the Aberdeenshire coastline, resulting in survey effort of $100 \mathrm{~h}$ with visibility $\geqslant 1 \mathrm{~km}$ and Beaufort sea state 4 or less. Vessel-based surveys took place in every calendar month between March and October, with the number of surveys per month ranging from one to eight (Table 3). Over $70 \%$ of vessel-based survey effort $(75.2 \mathrm{~h})$ was carried out in sea states of Beaufort 2 or less. The majority of vessel surveys $(\mathrm{N}=27)$ ran north along the coast between Stonehaven and Aberdeen (see Figure 1), covering a total return distance of $48 \mathrm{~km}$ and a resulting total survey effort of $89.7 \mathrm{~h}$. The remaining surveys $(\mathrm{N}=2)$ ran south between Stonehaven and Inverbervie, covering an approximate total return distance of $50 \mathrm{~km}$ and accounting for a total survey effort of $6.5 \mathrm{~h}$.

Table 2. Monthly summary of land-and vessel-based survey effort conducted in Aberdeenshire waters between 1999 and 2001.

\begin{tabular}{lccc}
\hline Month & $\begin{array}{c}\text { Land effort } \\
(\mathrm{min})\end{array}$ & $\begin{array}{c}\text { Vessel effort } \\
(\mathrm{min})\end{array}$ & $\begin{array}{c}\text { Total effort } \\
(\mathrm{min})\end{array}$ \\
\hline January & 120 & 0 & 120 \\
February & 735 & 0 & 735 \\
March & 2125 & 195 & 2320 \\
April & 2702 & 200 & 2902 \\
May & 1460 & 1813 & 3273 \\
June & 1700 & 803 & 2503 \\
July & 510 & 505 & 1015 \\
August & 2320 & 1383 & 3703 \\
September & 395 & 630 & 1025 \\
October & 770 & 245 & 1015 \\
November & 270 & 0 & 270 \\
December & 0 & 0 & 0 \\
Total & 13,107 & 5774 & 18,881 \\
\hline
\end{tabular}


Table 3. Frequency of bottlenose dolphin sightings and number of individuals per 60 min of search effort in Aberdeenshire waters between 1999 and 2001.

\begin{tabular}{|c|c|c|c|c|c|c|}
\hline \multirow[b]{3}{*}{ Month } & \multicolumn{6}{|c|}{ Survey method } \\
\hline & \multicolumn{2}{|c|}{ Land-based } & \multicolumn{2}{|c|}{ Vessel-based } & \multicolumn{2}{|c|}{ Combined } \\
\hline & $\begin{array}{l}\text { SPUE } \\
(\mathrm{N})\end{array}$ & $\begin{array}{c}\text { IPUE } \\
(\mathrm{N})\end{array}$ & $\begin{array}{c}\text { SPUE } \\
(\mathrm{N})\end{array}$ & $\begin{array}{c}\text { IPUE } \\
(\mathrm{N})\end{array}$ & $\begin{array}{c}\text { SPUE } \\
(\mathrm{N})\end{array}$ & $\begin{array}{c}\text { IPUE } \\
(\mathrm{N})\end{array}$ \\
\hline January & 0 & 0 & - & - & 0 & 0 \\
\hline February & $\begin{array}{c}0.33 \\
(4)\end{array}$ & $\begin{array}{l}4.57 \\
(56)\end{array}$ & - & - & $\begin{array}{c}0.33 \\
(4)\end{array}$ & $\begin{array}{l}4.57 \\
(60)\end{array}$ \\
\hline March & $\begin{array}{l}0.42 \\
(15)\end{array}$ & $\begin{array}{c}3.08 \\
(109)\end{array}$ & $\begin{array}{c}0.62 \\
(2)\end{array}$ & $\begin{array}{c}1.23 \\
(4)\end{array}$ & $\begin{array}{l}1.04 \\
(17)\end{array}$ & $\begin{array}{c}4.31 \\
(113)\end{array}$ \\
\hline April & $\begin{array}{l}0.42 \\
(19)\end{array}$ & $\begin{array}{l}3.15 \\
(142)\end{array}$ & $\begin{array}{c}0.30 \\
(1)\end{array}$ & $\begin{array}{l}4.20 \\
(14)\end{array}$ & $\begin{array}{l}0.72 \\
(20)\end{array}$ & $\begin{array}{c}7.35 \\
(156)\end{array}$ \\
\hline May & $\begin{array}{l}0.45 \\
(11)\end{array}$ & $\begin{array}{c}5.14 \\
(125)\end{array}$ & $\begin{array}{l}0.56 \\
(17)\end{array}$ & $\begin{array}{c}4.53 \\
(137)\end{array}$ & $\begin{array}{l}1.01 \\
(28)\end{array}$ & $\begin{array}{c}9.67 \\
(262)\end{array}$ \\
\hline June & $\begin{array}{c}0.11 \\
(3)\end{array}$ & $\begin{array}{l}1.24 \\
(35)\end{array}$ & $\begin{array}{c}0.15 \\
(2)\end{array}$ & $\begin{array}{l}0.97 \\
(13)\end{array}$ & $\begin{array}{c}0.26 \\
(5)\end{array}$ & $\begin{array}{l}2.21 \\
(48)\end{array}$ \\
\hline July & 0 & 0 & 0 & 0 & 0 & 0 \\
\hline August & $\begin{array}{c}0.05 \\
(2)\end{array}$ & $\begin{array}{c}0.23 \\
(9)\end{array}$ & $\begin{array}{c}0.04 \\
(1)\end{array}$ & $\begin{array}{l}0.52 \\
(12)\end{array}$ & $\begin{array}{c}0.09 \\
(3)\end{array}$ & $\begin{array}{l}0.75 \\
(21)\end{array}$ \\
\hline September & 0 & 0 & 0 & 0 & 0 & 0 \\
\hline October & $\begin{array}{c}0.47 \\
(6)\end{array}$ & $\begin{array}{l}5.14 \\
(66)\end{array}$ & 0 & 0 & $\begin{array}{c}0.47 \\
(6)\end{array}$ & $\begin{array}{l}5.14 \\
(66)\end{array}$ \\
\hline November & $\begin{array}{c}0.22 \\
(1)\end{array}$ & $\begin{array}{c}0.67 \\
(3)\end{array}$ & - & - & $\begin{array}{c}0.22 \\
(1)\end{array}$ & $\begin{array}{c}0.67 \\
(3)\end{array}$ \\
\hline December & - & - & - & - & - & - \\
\hline Total & $\begin{array}{l}2.47 \\
(61)\end{array}$ & $\begin{array}{l}23.22 \\
(545)\end{array}$ & $\begin{array}{l}1.67 \\
(23)\end{array}$ & $\begin{array}{l}11.45 \\
(180)\end{array}$ & $\begin{array}{l}4.14 \\
(84)\end{array}$ & $\begin{array}{l}34.67 \\
(725)\end{array}$ \\
\hline
\end{tabular}

IPUE, number of observed individuals per 60 min search effort; SPUE, number of sightings per $60 \mathrm{~min}$ search effort.

\section{Land-based surveys}

Bottlenose dolphins were sighted on 61 occasions during dedicated land-based surveys, resulting in over $70 \mathrm{~h}$ of dolphin observation time. Further records of opportunistic sightings $(\mathrm{N}=262)$ provided by Sea Watch Foundation volunteers were additionally noted for the same study period, although excluded from the present analysis since too few observations were associated with quantified effort. The duration of effort-related sightings ranged from 5 to $280 \mathrm{~min}$ ( $\mathrm{mean}=71.9 \mathrm{~min}, \mathrm{SD}=6.1 \mathrm{~min})$, and the overall mean SPUE for bottlenose dolphins along the Aberdeenshire coast was 0.43 , with a mean IPUE of 3.71 animals. The number of land-based observations varied with Beaufort sea state, accounting for a SPUE of 0.80, 0.24, $0.28,0.22$ and 0.45 for sea states 0 to 4 respectively.

The SPUE and IPUE of bottlenose dolphins varied markedly between months (Table 3 ), with the number of sightings and individuals higher during spring than in any other season (Kruskal-Wallis tests: $\mathrm{H}=8.40$, $\mathrm{df}=3$, $P=0.004 ; \mathrm{H}=7.42, \mathrm{df}=3, P=0.006$ respectively). Group size ranged from 1 to 32 individuals (mean $=9.0$, $\mathrm{SD}=6.8)$, with $66 \%$ of groups encountered $(\mathrm{N}=41)$ containing eight animals or less (Figure 3). Dolphins were

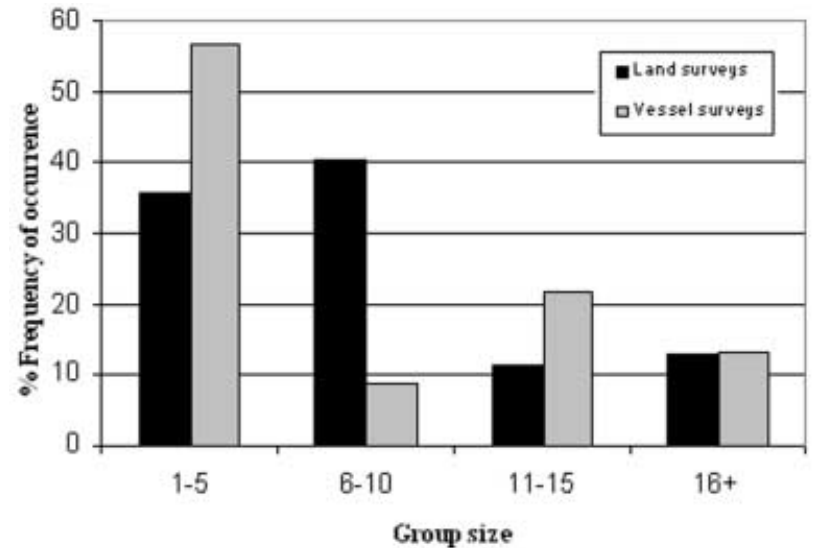

Figure 3. Occurrence of dolphin group sizes observed during land- and vessel-based surveys in Aberdeenshire waters between 1999 and 2001 .

observed at four of the six survey sites (Aberdeen harbour, Girdleness, Nigg and Cove), with the highest frequency of sightings occurring at Aberdeen harbour $(\mathrm{N}=53)$. When corrected for survey effort, Nigg recorded the highest SPUE of 0.71, with Aberdeen harbour having a SPUE of 0.46. No observations of bottlenose dolphins were made at either Collieston or Balmedie despite considerable survey effort at Collieston $(22.6 \mathrm{~h})$. There was no significant difference in the mean group size of dolphins between months or between seasons.

Calves were present in $51 \%(\mathrm{~N}=29)$ of those groups for which composition could be assessed $(\mathrm{N}=57)$ and were observed primarily between February and May. Juveniles were observed in $67 \%(\mathrm{~N}=38)$ of assessed groups and were also mainly observed from February to May. The proportion of calves was highest during spring (KruskalWallis $\mathrm{H}=8.05, \mathrm{df}=3, P=0.045)$, although no significant variation in the proportion of calves, juveniles or immatures could be detected between individual months.

Habitat use was assessed during most encounters ( $\mathrm{N}=59$ ), with behavioural data recorded for $97 \%$ of groups. The most frequently recorded categories of behaviour were social and normal swim, which were observed in $46 \%(\mathrm{~N}=27)$ and $44 \%(\mathrm{~N}=26)$ of groups respectively. Behaviour varied considerably between sites, with foraging being observed only at Aberdeen harbour and Nigg. At these two sites foraging accounted for $24 \%$ and $17 \%$ of the total behavioural data respectively. However, since foraging was only recorded on occasions that prey was observed, it is likely that this behaviour has been underestimated. At Cove and Girdleness, the predominant behaviour was travel, and normal swim, accounting for $80 \%$ and $68 \%$ of observations respectively. Social behaviour was recorded at all sites but most often at Cove and Nigg, where it accounted for $33 \%$ of observed behaviours. Milling was recorded only at Aberdeen harbour, where it was observed during $12 \%$ of encounters, while resting was not observed during any land-based surveys.

\section{Vessel-based surveys}

Bottlenose dolphins were sighted on 23 occasions, during $39 \%$ of vessel surveys $(\mathrm{N}=10)$, with a minimum total of 180 animals recorded (based on minimum group counts). The mean overall SPUE for bottlenose dolphins 
Table 4. Photo-identification data and corresponding Moray Firth ID codes for 12 animals catalogued in Aberdeenshire waters between April and August 2001.

\begin{tabular}{ccccc}
\hline $\begin{array}{c}\text { Aberdeen- } \\
\text { shire } \\
\text { ID code }\end{array}$ & $\begin{array}{c}\text { Moray } \\
\text { Firth } \\
\text { ID code }\end{array}$ & $\begin{array}{c}\text { Encounter } \\
\text { date }\end{array}$ & $\begin{array}{c}\text { Re-sight } \\
\text { date }\end{array}$ & $\begin{array}{c}\text { Re-sight } \\
\text { period } \\
\text { (days) }\end{array}$ \\
\hline A01 & 060 & $23 / 06 / 2001$ & $04 / 08 / 2001$ & 42 \\
A02 & 456 & $04 / 08 / 2001$ & $11 / 08 / 2001$ & 7 \\
A04 & 064 & $04 / 08 / 2001$ & - & - \\
A05 & 006 & $12 / 05 / 2001$ & $23 / 06 / 2001$ & 42 \\
A07 & - & $23 / 06 / 2001$ & - & - \\
A08 & 885 & $23 / 06 / 2001$ & - & - \\
A10 & 788 & $28 / 04 / 2001$ & $12 / 05 / 2001$ & 14 \\
A12 & 214 & $05 / 05 / 2001$ & $23 / 06 / 2001$ & 49 \\
A13 & 008 & $23 / 06 / 2001$ & - & - \\
A14 & 805 & $28 / 04 / 2001$ & $05 / 05 / 2001$ & 7 \\
A15 & 209 & $23 / 06 / 2001$ & - & - \\
A17 & 234 & $05 / 05 / 2001$ & $12 / 05 / 2001$ & 7 \\
\hline
\end{tabular}

ID, identification.

was 0.35 , with mean IPUE of 2.65 animals. Dolphins were consistently located throughout the majority of the northern sector between Stonehaven and Aberdeen, with a cluster of sightings $(\mathrm{N}=15)$ occurring along the coastline between Cove and Aberdeen harbour (Figure 2). No observations of bottlenose dolphins were made south of Stonehaven, although it should be noted that only two surveys took place along this southern sector, both of which were confined to the summer months when bottlenose dolphin sightings were scarce along much of the Aberdeenshire coast. Durations of vessel-based sightings ranged from 2 to $120 \mathrm{~min} \quad($ mean $=24.2 \mathrm{~min}$, $\mathrm{SD}=32.4 \mathrm{~min}$ ), resulting in almost $9 \mathrm{~h}$ of contact time.

The SPUE and IPUE differed between seasons (Kruskal-Wallis tests: $\mathrm{H}=8.09, \quad \mathrm{df}=3, \quad P=0.004$; $\mathrm{H}=9.75, \mathrm{df}=3, P=0.002$ respectively), with the highest number of dolphins observed during the spring months (Table 3). Group size ranged from 1 to 28 individuals (mean=7.8, $\mathrm{SD}=7.4$ ), with over half of the total groups encountered $(\mathrm{N}=13)$ containing four animals or fewer (Figure 3). A solitary individual was sighted only once, whilst aggregations of 20 to 30 animals were also rare occurrences $(\mathrm{N}=2)$. All vessel-based observations occurred in Beaufort sea states 3 or less, with an overall SPUE of 1.94, 0.33, 0.17 and 0.23 observed for sea states 0 to 3 respectively.

Bottlenose dolphin calves were observed during seven surveys and were present in $44 \% \quad(\mathrm{~N}=10)$ of groups encountered in Aberdeenshire waters. A number of calves exhibited diagnostic features indicative of neonates, e.g. the presence of noticeable dorso-ventral foetal folds. Calves were observed only between the months of April and June, despite considerable survey effort from July to October (Table 3). However, it should also be noted that both the number of sightings and the number of animals observed remained low during this period (Table 3). Juveniles were also observed during seven surveys and were present in $39 \%$ of groups encountered $(\mathrm{N}=9)$. These encounters predominantly occurred between April and June, although a single observation of bottlenose dolphins in August did include two juveniles. Due to the small sample size, we combined both land- and vesselbased data to analyse seasonal variation in the incidence of calves and juveniles. There was significant seasonal variation in the proportion of calves with most being observed during the spring time $(\mathrm{H}=8.88, \mathrm{df}=3$, $P=0.031$ ). However, no significant variation was found in the proportion of either juveniles or immatures between months or seasons.

The majority of bottlenose dolphin groups encountered during vessel-based surveys $(\mathrm{N}=21)$ were observed travelling. Bow-riding animals were observed in $43 \%(\mathrm{~N}=9)$ of travelling groups. Foraging was rarely observed during vessel-based surveys, occurring in just $13 \% \quad(\mathrm{~N}=3)$ of encountered groups, and confined primarily to the mouth of Aberdeen harbour. Dolphin groups exhibiting social behaviour accounted for $26 \%(\mathrm{~N}=6)$ of assessed schools, while resting behaviour was not observed in any assessed groups encountered during vessel-based surveys.

During six vessel-based surveys (April to August 2001), 12 sufficiently well marked dolphins were photographed (Table 4). Over half of these well-marked individuals $(\mathrm{N}=7)$ were re-sighted within Aberdeenshire waters during the remainder of the study. The elapsed time between re-sightings ranged from seven (Al4 and A17) to 49 days (A12) (mean=24.0, $\mathrm{SD}=19.3)$. Of these 12 animals, eight had been sighted in the inner Moray Firth during and/or prior to 2001 (University of Aberdeen, unpublished data), whilst nine had previously been sighted off St Andrews (University of Aberdeen \& Sea Mammal Research Unit, unpublished data). Six of the Aberdeenshire animals (A01, A05, A12, A13, A15, and A17) were recorded at all three sites.

\section{DISCUSSION}

The data presented here, as well as those collected opportunistically by the Sea Watch Foundation reveal the occurrence throughout the year of North Sea bottlenose dolphins along the Aberdeenshire coast, a site that lies over $200 \mathrm{~km}$ from the specially designated SAC for this population. The data also reveal a strong seasonality in the relative abundance of bottlenose dolphins in Aberdeenshire waters, and the regular seasonal presence of calves within this region. The behavioural data presented here suggest that bottlenose dolphins in Aberdeenshire waters feed in certain key areas, and are rarely observed feeding at other locations along the coastline. Aberdeen harbour is Europe's largest centre of support for the exploration and production of oil and gas in the North Sea, a ferry terminal, and an important port for the Scottish fisheries industry. Given the use of this site as a feeding area by dolphins, and the high level of boat traffic within the region, disturbance of dolphins could be a conservation issue, although Sini et al. (2005) found evidence of habituation of bottlenose dolphins to boat traffic in the harbour.

The results of the present systematic surveys are consistent with both the increase in opportunistic sightings of bottlenose dolphins between Fraserburgh and St Andrews during the mid 1990s (Weir \& Stockin, 2001), and the spring occurrence of bottlenose dolphins reported by Carter et al. (2004) within the River Dee estuary (Aberdeen harbour) during 1995 and 1996. Such reported 
increases in the occurrence of bottlenose dolphins outside of Moray Firth waters led Wilson et al. (2004) to examine the possibility of a range expansion of this North Sea population. Using photo-identification of bottlenose dolphins within and beyond the SAC, and citing an increase in the incidence of harbour porpoise mortality attributable to violent interactions with bottlenose dolphins along the north-east coast of Scotland (Ross \& Wilson, 1996), Wilson et al. (2004) concluded that a range extension in North Sea bottlenose dolphins was evident. Interestingly, porpoise strandings data collected specifically from along the Aberdeenshire coast during the same time frame (1992 to 2003) reveal no significant increase in mortality attributable to bottlenose dolphins within this region ( $\mathrm{R}$. Reid, personal communication), despite results of the present study suggesting the regular use of these waters by bottlenose dolphins, at least during the spring.

There are numerous potential explanations for the seasonal variation in the presence of bottlenose dolphins along the Aberdeenshire coast. These include factors such as the movement of prey species, requirement for suitable calving conditions, and inter-specific competition and/or associations with other cetacean species. Cetacean distribution is often best explained by prey availability, which may in turn be influenced by oceanographic features (Evans, 1990). Since the Aberdeenshire coast has numerous rivers with salmon runs, and salmon comprise a significant portion of the diet of North Sea bottlenose dolphins (e.g. Santos et al., 2001), the availability of salmon may be at least partly responsible for the seasonal movement of bottlenose dolphins into the area.

Within the reported range of North Sea bottlenose dolphins, estuarine areas, inshore bays, and river mouths have repeatedly been found to be sites of high occurrence (e.g. Hastie et al., 2004), probably since such environments are typically characterized by high levels of primary productivity and prey abundance. Indeed, it is possible that the increased occurrence of bottlenose dolphins off Aberdeen harbour during the spring is correlated with the return to spawn of multi-sea-winter salmon (fish that enter rivers prior to 1 May). Moreover, the decrease in dolphin sightings in Aberdeenshire during late summer may also reflect an increase in salmonid availability in neighbouring Moray Firth and Firth of Forth waters, since salmonids are known to spawn at different times in different regions (Smith \& Smith, 1997). Given the low frequency of observations of foraging behaviour elsewhere along the Aberdeenshire coast, it would appear that Aberdeen harbour is a key feeding site, and those animals observed travelling outside of this region may be commuting between areas of suitable prey density.

An alternative (but not mutually exclusive) hypothesis for the seasonal presence of bottlenose dolphins in Aberdeenshire waters is linked to reproduction. Whilst calves can be observed throughout the year in UK waters, little is known about the reproductive cycle of North Sea bottlenose dolphins. Seasonal variation in the incidence of sightings of calves was evident in the present study, and has also been observed in bottlenose dolphin populations elsewhere in the world (e.g. Urian et al., 1996). In Aberdeenshire waters, bottlenose dolphin calves were present all year round, but the proportion of calves increased during the spring. However, since the timing of calving typically reflects cycles of prey availability or predation pressures (Mann et al., 2000), we suggest that reproduction alone is not the key explanation for the increased occurrence of bottlenose dolphins in Aberdeenshire waters during the spring.

Another factor that may be influencing the seasonal trend of bottlenose dolphins in the present study relates to interactions with other cetacean species. The seasonal occurrence of bottlenose dolphins within Aberdeenshire waters contrasts with that of other cetacean species found along this coastline, namely the harbour porpoise and white-beaked dolphin (Lagenorhynchus albirostris) (Weir \& Stockin, 2001). Predation is considered to be an important factor affecting dolphin distribution, although potential threats posed by killer whales (Orcinus orca) would be low considering that killer whales are rarely recorded in Aberdeenshire waters (Weir \& Stockin, 2001), and given that there is no evidence of predation on bottlenose dolphins by killer whales or large sharks anywhere around northern Scotland.

Photo-identification undertaken in the present study concurs with Wilson et al. (2004) in confirming the presence of North Sea dolphins within Aberdeenshire coastal waters. More importantly, the frequency and regularity of bottlenose dolphin presence in Aberdeenshire waters supports the contention that this coast is used far more extensively than previously reported (Wilson et al., 2004). The re-sighting rates achieved in the present study suggest that at least a proportion of the Moray Firth population utilizes the Aberdeenshire coast with some regularity.

The data presented here represent the first long-term systematic study of bottlenose dolphins in the coastal waters of Aberdeenshire and illustrate the importance of the region for North Sea bottlenose dolphins. Despite evidence of seasonality, the results of the present study reflect the year-round occurrence of bottlenose dolphins in Aberdeenshire waters. These findings have important implications, especially since this coastline does not currently form part of the SAC designated for the conservation of this population. This is particularly critical given the importance of Aberdeen harbour for feeding, the likely use of Aberdeenshire waters as a nursery area for this population, and the potential sources of disturbance within this region, especially heavy shipping traffic and dredging activity associated with Aberdeen harbour. Further research on this population along the Aberdeenshire coast is needed to fully evaluate the importance of these waters, and to establish whether the current $\mathrm{SAC}$ is adequate to conserve this protected population.

The authors wish to acknowledge the skipper of MV 'Tranquillity', Brian Bartlett and thank (in alphabetical order) the volunteer observers who assisted with the surveys: Sarah Canning, Ciáran Cronin, Kevin Hepworth, David Simmons and Andy Upton. Special thanks to Peter Evans (Sea Watch Foundation) for assisting with the logistics of this project, and to Paul Thompson (University of Aberdeen), Peter Evans and Mark Orams (Massey University) for reviewing earlier drafts of this manuscript. Additional thanks go to Bob Reid (SAC Veterinary Science Division) and Fernando Ugarte for their communications regarding this manuscript. In addition, we wish to thank Phil Hammond (Sea Mammal Research Unit) and Paul Thompson for allowing the inclusion of the fin match data 
presented here. We wish to acknowledge Vicky Binedell and Denny Meyer (Massey University) for their statistical advice and Dagmar Fertl (Geo-Marine Inc.), Ingrid Visser (Orca Research Trust), and three anonymous referees for their comments, which improved this manuscript. K.A.S. was supported by the University of Aberdeen as an honorary research assistant during this research project, which was kindly funded by Shell UK Exploration and Production Ltd.

\section{REFERENCES}

Carter, T.J., Pierce, G.J. \& Hislop, J.R.G., 2004. Estimating marine mammal abundance and impact on salmonids in two Scottish estuaries. European Research on Cetaceans, 15, 53-55.

Durban, J.W., Elston, D.A., Ellifrit, D.K., Dickson, E., Hammond, P.S. \& Thompson, P.M., 2005. Multisite markrecapture for cetaceans: population estimates with Bayesian model averaging. Marine Mammal Science, 21, 80-92.

Evans, P.G.H., 1990. European cetaceans and seabirds in an oceanographic context. Lutra, 33, 95-125.

Fertl, D., 1994. Occurrence patterns and behaviour of bottlenose dolphins (Tursiops truncatus) in the Galveston ship channel, Texas. Texas Fournal of Science, 46, 299-317.

Hammond, P.S. et al., 2002. Abundance of harbour porpoise and other cetaceans in the North Sea and adjacent waters. Fournal of Applied Ecology, 39, 361-376.

Hastie, G.D., Wilson, B., Wilson, L.J., Parsons, K.M. \& Thompson, P.M., 2004. Functional mechanisms underlying cetacean distribution patterns: hotspots for bottlenose dolphins are linked to foraging. Marine Biology, 144, 397-403.

Mann, J., 1999. Behavioral sampling methods for cetaceans: a review and critique. Marine Mammal Science, 15, 102-122.

Mann, J., Connor, R.C., Barre, L.M. \& Heithaus, M.R.M., 2000. Female reproductive success in bottlenose dolphins (Tursiops sp.): life history, habitat, provisioning, and group-size effects. Behavioral Ecology, 11, 210-219.

Reeves, R.R., Smith, B.D., Crespo, E.A. \& Notarbartolo di Sciara, G., 2003. Dolphins, whales and porpoises. 2002-2010 Conservation Action Plan for the World's Cetaceans. Gland, Switzerland: IUCN/SSC Cetacean Specialist Group.

Ross, H.M. \& Wilson, B., 1996. Violent interactions between bottlenose dolphins and harbour porpoises. Proceedings of the Royal Society B, 263, 283-286.
Santos, M.B., Pierce, G.J., Reid, R.J., Patterson, I.A.P., Ross, H.M. \& Mente, E., 2001. Stomach contents of bottlenose dolphins (Tursiops truncatus) in Scottish waters. Fournal of the Marine Biological Association of the United Kingdom, 81, 873-878.

Sini, M.I., Canning, S.J., Stockin, K.A. \& Pierce, G.J., 2005. Bottlenose dolphins around Aberdeen harbour, north-eastern Scotland: a study of habitat utilization and the potential effects of boat traffic. Fournal of the Marine Biological Association of the United Kingdom, 85, 1547-1554.

Smith, I.P. \& Smith, G.W., 1997. Tidal and diel timing of river entry by adult Atlantic salmon returning to the Aberdeenshire Dee, Scotland. Fournal of Fish Biology, 50, 463474.

Stevick, P.T., Palsbøll, P.J., Smith, T.D., Bravington, M.V. \& Hammond, P.S., 2001. Errors in identification using natural markings: rates, sources, and effects on capture-recapture estimates of abundance. Canadian Fournal of Fisheries and Aquatic Sciences, 58, 1861-1870.

Urian, K.W., Duffield, D.A., Read, A.J., Wells, R.S. \& Shell, E.D., 1996. Seasonality of reproduction in bottlenose dolphins Tursiops truncatus. Fournal of Mammalogy, 77, 394-403.

Weir, C.R. \& Stockin, K.A., 2001. The occurrence and distribution of bottlenose dolphins (Tursiops truncatus) and other cetacean species in the coastal waters of Aberdeenshire, Scotland. Sea Watch Foundation Report, Oxford, 1-68.

Wells, D.E., Campbell, L.A., Ross, H.M. \& Thompson, D., 1994. Organochloride residues in harbour porpoise and bottlenose dolphins stranded on the coast of Scotland, 1980-1991. Science of the Total Environment, 151, 77-99.

Wilson, B., Hammond, P.S., Reid, R.J., Grellier, K. \& Thompson, P.M., 2004. Considering the temporal when managing the spatial: a population range expansion impacts protected areas-based management for bottlenose dolphins. Animal Conservation, 7, 1-8.

Wilson, B., Hammond, P.S. \& Thompson, P.M., 1999. Estimating size and assessing trends in a coastal bottlenose dolphin population. Ecological Applications, 9, 288-300.

Zar, J.H., 1996. Biostatistical analysis. London: Prentice-Hall International (UK) Ltd.

Submitted 26 September 2005. Accepted 26 November 2005. 
Examining the importance of Aberdeenshire

(UK) coastal waters for North Sea

bottlenose dolphins (Tursiops truncates)

Stockin, K. A.

2006

http://hdl.handle.net/10179/9681

22/04/2023 - Downloaded from MASSEY RESEARCH ONLINE 